\title{
GARRETT E SEU CONVITE À VIAGEM
}

\author{
Patrícia Cardoso*
}

... um livm de viagem onde a viagem seja o livmo o ser do livm é a viagem por isso começo pois a viagem é o comeco e volto e revolto pois na volla recomeço reconheço remeço um livro ...

Haroldo de Campos, Galárias

iagens na minha terra inicia-se com uma referência à muito particular viagem empreendida por Xavier de Maistre cuja função é, a princípio, declarar a opção do narrador pela trajetória por uma geografia real, uma vez que sua viagem cobrirá o espaço entre Lisboa e Santarém.

Que viaje à roda do seu quarto quem está à beira dos Alpes, de Inverno, em Turim, que é quase tão frio quanto Sampetesburgo - entende-se. Mas com este clima, com este ar que Deus nos deu, onde a laranjeira cresce na horta e o mato é de murta, o próprio Xavier de Maistre que aqui escrevesse ia até o quintal.'

* Universidade Federal do Paraná

1 GARRETT, Almeida. Vagens na minha terra. Lisboa: Europa-América, 1972, p. 9. 
O tom irônico do narrador, que atribui a peculiaridade da narrativa de de Maistre à falta de opção climática, não apenas serve para ridicularizar a situação criada pelo autor francês, mas também para, de maneira indireta, desqualificar a experiência empreendida pelo outro "viajante", que escolhe percorrer um trajeto interior, subjetivo, para o qual a exígua geografia representada pelo quarto é o ponto de partida.

Condescendei em acompanhar-me na minha viagem. Seguiremos por pequenas jornadas, rindo, ao longo do caminho, dos viajantes que viram Roma e Paris. Nenhum obstáculo poderá deter-nos; e, entregando-nos jovialmente a nossa imaginação, segui-la-emos por toda parte onde ela se compraza em nos conduzir. $^{2}$

Se levarmos em conta esse caráter de exploração da subjetividade que encontramos na Viagem à roda de meu quarto, poderemos desdobrar a opção do narrador garrettiano em outra: uma narrativa que apresente o mundo empírico e reflita sobre ele de maneira objetiva, ou seja, exatamente o oposto do que encontramos no texto de de Maistre.

Diante de um tal desdobramento, somos levados a supor que Garrett recusa a ambivalência que frequientemente acompanha o tema da viagem principalmente quando se trata daquelas que se dão fora dos limites de um quarto. Afinal, é grande o número de textos de ficção que, através da narrativa de viagem e do encontro que ela promove com aquilo que está fora de nosso cotidiano, representam o processo de revelação, de libertação, de aspectos desconhecidos ou encobertos de nossa própria personalidade - individual ou coletiva ${ }^{3}$.

Mas, antes de tirarmos conclusões precipitadas, devemos ouvir o narrador, que novamente se apresenta para esclarecimentos. Não se trata, como já estávamos inclinados a concluir, de uma viagenzinha qualquer, "sem metafísica", para lembrar as palavras de Álvaro de Campos, por sinal um

2 DE MAISTRE, Xavier. Viagem à roda de meu quarto. São Paulo: Estação Liberdade, 1989. p. 7.

3 Como se sabe, o simbolismo que envolve o tema da viagem extrapola os limites da moderna literatura de ficção, podendo ser encontrado nas mais diversas culturas desde tempos remotos. 
viajante com larga experiência. $\mathrm{O}$ narrador reivindica para sua obra nada mais nada menos do que a condição de

símbolo, de mito (...) mito porque, - porque... (...) declaro abertamente ao benévolo leitor a profunda ideia que está oculta debaixo desta ligeira aparência de uma viagenzita que parece feita a brincar, e no fim de contas é uma coisa, séria, grave (...). Ora nesta minha viagem Tejo arriba está simbolizada a marcha do nosso progresso social (...). Tomarei cuidado de lho lembrar de vez em quando, porque receio muito que se esqueça ${ }^{4}$.

Como já havíamos notado em relação à abertura do livro, as palavras de esclarecimento têm aqui seu objetivo alterado e parecem mais confundir do que esclarecer. Também neste trecho, a ironia dá o tom da informação. A afirmação de que se trata de uma narrativa com objeti vos complexos e clevados é abalroada pela falta de seriedade no tratamento da questão, o que acaba por deixar claro para um leitor até aqui desatento - o trecho corresponde ao início do capítulo II - que, juntamente com a viagem a Santarém, a grande atração dessa narrativa é o narrador.

Em meio a tantas informações truncadas, é possível identificar nessa narrativa de viagem um processo qualquer de libertação, que entretanto não diz. respeito ao indivíduo que organiza a narrativa, mas à própria narrativa, que não parece obedecer a nenhum interesse externo, ou apresentar-se como fio condutor de uma mensagem previamente definida. O narrador deixa-se levar pelas digressões sem se preocupar demais com as eventuais fugas de assunto que elas possam representar. Na verdade, da maneira como se desenvolve a narrativa, torna-se difícil pensar em uma fuga. Todos os assuntos podem ser adequados.

Quando entra em campo o elemento digressão, instantaneamente é lembrada a ligação desse narrador de Garrett com o Tristram Shandy de Stern. a respeito de quem José Paulo Paes diz que faz questão de colocar-se entre leitor e narrativa não como um mediador, mas como o centro das atenções:

a digressão é um artifício deliberadamente utilizado no Tristram Shandy para desviar o foco de interesse, dos sucessos em si para

4 GARRETT, Almeida, op. cit., p. 14-15. 
a maneira por que são narrados. E esse desvio faz com que a luz incida mais no narrador do que em seus personagens $(\ldots)^{5}$.

Também o narrador das Viagens parece despreocupado com seu eventual excesso de exposição e, tal como acontece com Tristram, ao iluminar tão ostensivamente o lugar que ocupa na narrativa, acaba por atrair a atenção do leitor para o processo em si de construção dessa narrativa, deixando em segundo plano o desenrolar dos fatos relativos ao enredo da viagem a Santarém.

Voltando ao início destas considerações é, então, por um caminho tortuoso que Garrett se aproxima do modelo que ele parece recusar para em seguida superá-lo. No entanto, essa aproximação não se dá pelo abandono dos elementos objetivos relativos à viagem, mas da exploração pelo narrador dos mecanismos que estruturam a narrativa, de forma a promover um movimento pendular entre os campos subjetivo e objetivo, que cria entre eles uma interdependência.

Como veremos, é imprescindível para os objetivos de Garrett que a viagem de seu personagem decorra em uma geografia real e, mais que isso, específica. E é igualmente imprescindível que sobre ela sejam lançados o olhar e as observações do narrador, de tal forma que o resultado não seja uma descrição da paisagem ou das impressões que ela causa no viajante, mas uma reflexão sobre o rumo seguido pelo seu país. Nunca é demais lembrar que Afonso Henriques parte de Santarém para a conquista de Lisboa e para a conseqüente consolidação do reino português.

Uma vez que tal procedimento do narrador não é declarado, a eventual mensagem por trás da viagem tem seu sentido obscurecido, o que requer do leitor que investigue em que medida o narrador de fato faz de sua narrativa um mito, um símbolo. Como em um processo iniciático, apenas depois de tomar conhecimento desses mecanismos o leitor estará apto a conhecer o que está à espera do narrador nos arredores de Santarém: não será sem surpresa que descobrirá tratar-se de uma nova narrativa, que se entretecerá à primeira. Sobre ela o narrador dirá:

O que eu vou contar não é um romance, não tem aventuras enredadas, peripécias, situações e incidentes raros; é uma história simples e singela, sinceramente contada e sem pretensão. ${ }^{6}$

5 PAES, José Paulo. Stern ou o horror à linha reta. In: STERN, Laurence. $A$ vida e as opiniöes do cavalheiro Tristram Shandy. Rio de Janeiro: Nova Fronteira, 1984. p. 34-35.

6 GARRETT, op. cit., p. 49. 
O leitor, já experiente no trato com um narrador tão pouco fidedigno, não se surpreenderá ao perceber que a nova narrativa, protagonizada por Carlos e Joaninha, tem todos os ingredientes do típico romance romântico, não cabendo, portanto, na descrição que dela faz o narrador. Cabe a esse leitor perguntar o que faz um enredo tão pouco original em meio a essa outra narrativa que parece perseguir a originalidade. Para obter a resposta, novamente ele precisará voltar sua atenção para a estruturação da narrativa, verificando seu papel na história.

Para tanto precisará considerar, em primeiro lugar, que a história de Carlos e Joaninha serve como um elo de ligação entre o narrador e o lugar para onde se dirige: um pouco antes de chegar à cidade de Santarém, quando ainda está no vale, ele toma conhecimento do início dessa história cujo desenrolar dividirá a cena com a descrição da visita do narrador à cidade. Até aí, o leitor está diante de duas narrativas de natureza distinta, pois a principal delas pretende ser um registro das andanças de um narrador com um forte apelo verídico - há no texto várias marcas que fazem coincidir o personagem narrador com a figura do próprio autor. Já a narrativa secundária origina-se da sugestão de romance que um determinado ambiente evoca

Pareceu-me entrever uma cortina branca... e um vulto por detrás... Imaginação decerto! Se o vulto fosse feminino!... Era completo o romance. ${ }^{7}$

Segue-se um diálogo entre o narrador e um companheiro de viagem que concretiza aquilo que o narrador identifica apenas como possibilidade, uma vez que esse companheiro afirma a existência real de tal vulto feminino. Ainda que, como vimos acima, o narrador faça a ressalva de não se tratar essa narrativa que está prestes a encadear-se à principal de um romance - de uma ficção - , as reviravoltas da trama tendem a anular suas palavras, fazendo o leitor acompanhá-la de maneira diversa. E, por fim, o próprio narrador se encarrega de reforçar essa tendência, numa atitude característica de sua "personalidade":

Mas basta de vale que é tarde (...) Picar para Santarém, (...) que nos espera um bom jantar de amigo (...).

(...)

- Porquê? Já se acabou a história de Carlos e Joaninha? - diz

7 GARRETT, op. cil., p. 48. 
talvez a amável leitora.

- Não, minha senhora - responde o autor, mui lisonjeado da pergunta. - Não, minha senhora, a história não acabou, quase se pode dizer que ela ainda agora começa; mas houve mutação de cena. Vamos a Santarém, que lá se passa o segundo acto. ${ }^{8}$

Munido de sua ironia, leva ao extremo a concepção romântica que atribui uma força excepcional às histórias contadas nos lugares em que elas de fato se passaram, método que intensificaria a experiência do leitor ávido por ver-se diante de um passado idealmente reconstruido. Ocorre que, ao contrário do que sucederia se esse narrador estivesse completamente engajado no universo do Romantismo, ao chegar a Santarém, é uma ruína do passado que ele encontra, uma ruína nada imponente e muito menos digna de respeito, o que faz com que suas reflexões, que até ali recaíam sobre os mais diversos assuntos, concentremse em torno do destino de Portugal, de sua situação no presente, em grande medida pior do que aquela do passado, de que as ruínas são o símbolo.

Anteriormente, no início do livro e da viagem, o narrador já havia dado mostras de insatisfação com os monumentos históricos que encontrou pelo caminho - bem como com o engodo que constitui a crença dos autores românticos na possibilidade de recuperação do passado histórico. Diante do pinhal de Azambuja ele dirá

Este é que é o pinhal de Azambuja?

Não pode ser.

Esta, aquela antiga selva temida quase religiosamente como um bosque druídico? E eu, que em pequeno nunca ouvia contar uma história de Pedro Malas-Artes, que logo, em imaginação, lhe não pusesse a cena aqui perto!... Eu que esperava topar a cada passo com a cova do capitão Roldão e da dama Leonarda!...Oh! que ainda me faltava perder mais esta ilusão...

Se o presente dos sítios históricos nega a grandeza da própria história que neles se passou - seja ela verdadeira ou fictícia - como esperar que esses mesmos sítios possam fornecer material de pesquisa para a composição de obras de fundo

8 GARRETT, op. cit., p. 123.

9 Ibid, p. 25. 
histórico? Depois de tantas decepções, resta ao narrador esclarecer mais um ponto para seu crédulo leitor

Sim, leitor benévolo, e por esta ocasião te vou explicar como nós hoje em dia fazemos a nossa literatura. Já me não importa guardar segredo; depois desta desgraça não me importa já nada. Saberás pois, 6 leitor, como nosoutros fazemos o que te fazemos ler.

Trata-se de um romance, de um drama - cuidas que vamos estudar a história, a natureza, os monumentos, (...) as memórias da época? Não seja pateta, senhor leitor, nem cuide que nós o somos. 10

A partir desses aspectos é possível começar a identificar no enredo da história encadcada os elementos que compõem a tal mensagem obscurecida, o mito mesclado com o humor. A impossibilidade de pôr em prática o modelo romântico de recuperação do passado é fruto da experiência do narrador como viajante. Sua viagem pelo espaço revela a irreversível mudança provocada pela passagem do tempo. E, diante de tal constatação, não são as ruínas que o incomodam, mas a certeza de que se a história nacional - cheia de grandes momentos no passado - se desenrolasse no presente, ela necessariamente seria outra, desta vez sem glória.

Aos poucos o leitor se dá conta de que os elementos da escola romântica presentes na narrativa encadeada têm a função de sublinhar, através, principalmente, dos envolvimentos amorosos, a falta de perspectiva de Carlos, sua volubilidade natural, responsável por sua adesão a valores comprometedores. Aos poucos também, ele identificará nesse mesmo Carlos e em sua trajetória um símbolo do próprio país que, ao aderir a um novo modelo político e cultural, acaba por destruir os valores anteriores, responsáveis pelo que poderíamos chamar de uma identidade coletiva.

Tal como ocorre com a interdependência dos planos subjetivo c objetivo na estruturação da narrativa, não se trata neste ponto de promover uma recusa do novo Portugal na tentativa de voltar a um passado idealizado, mas de refletir sobre a necessidade de apoiar-se o novo país em aspectos ainda válidos do velho país. Nesse sentido, é importante a figura de Frei Dinis, representativa da problemática criada com a indiscriminada substituição de modelos. Antes de pôr em cena esse personagem, o narrador dirá

10 GARRETT, op. cit., p. 25 
Ora eu, que sou ministerial do Progresso, antes queria a oposição dos frades que a dos barões. $O$ caso estava em a saber conter $\mathrm{e}$ aproveitar.

O Progresso e a Liberdade perdeu, não ganhou.

Quando me lembra tudo isto, quando vejo os conventos em ruínas, os egressos a pedir esmola e os barões de berlinda, tenho saudades dos frades - não dos frades que foram, mas dos frades que podiam ser.

E sei que me não enganam poesias; que eu reajo fortemente com uma lógica inflexível contra ilusões poéticas em se tratando de coisas graves.

E sei que me não namoro de paradoxos, nem sou destes espíritos de contradição desinquieta que suspiram pelo que foi, e nunca estão contentes com o que é.

Frei Dinis tem uma conduta que o coloca como um dos "frades que podiam ser", pois encara com seriedade o sacerdócio, que chama de profissão, ainda que tenham sido pessoais os motivos que o levaram a fazer tal escolha. Ele é o oposto de Carlos, cujas escolhas profissionais, devendo-se igualmente a interesses pessoais, uma vez feitas, não sofrem qualquer reorientação no sentido de virem a servir à coletividade. $O$ mesmo desgosto familiar define as profissões de Frei Dinis e Carlos. No entanto, ao contrário do que acontece com Frei Dinis, que opta por um clero em franca decadência, Carlos escolhe o lado vencedor, $o$ lado dos barões. Quando se revela que Dinis e Carlos são pai e filho, a ameaça de cisão definitiva entre os dois lados - e os dois tempos - francamente opostos que eles representam chega a sua máxima tensão. Da mesma forma que a família de Dinis é destruída pelas diferenças inconciliáveis entre os dois personagens, a pátria tende a se deteriorar se não criar um ponto de equilíbrio entre o que foi no passado e o que pretende ser no futuro.

Para intensificar o impasse, próximo do fim da viagem, já de volta a Lisboa, o narrador, ao passar pelo vale encontra-se com Frei Dinis, com quem tem o seguinte diálogo

- Tivemos culpa nós, é certo; mas os liberais não tiveram menos.

- Erramos ambos.

- Erramos e sem remédio. A sociedade já não é o que foi, não

11 GARRETT, op. cit., p. 61. 
pode tornar a ser o que era; mas muito menos ainda pode ser o que é. $O$ que há de ser, não sei. Deus proverá. ${ }^{12}$

O diálogo, além de quebrar a impressão do leitor de que está diante de duas narrativas de natureza distinta, uma vez que nele interagem personagens de uma e outra, dá claramente a idéia de que o objetivo de Garrett é, antes de mais nada, buscar um caminho para o país. Caso esse caminho não seja encontrado, o destino nacional pode ser antevisto nas duas figuras que o narrador deixa para trás ao partir do vale

Eu levantei-me, contemplei-os ambos alguns segundos. Nenhum me deu mais atenção nem pareceu cônscio da minha estada ali. Sentia-me como na presença da morte e aterrei-me. ${ }^{13}$

Uma vez que Santarém é um ponto importante na história da configuração do território português, pode-se dizer que a viagem do narrador até lá seja na verdade uma viagem de volta. Volta à origem da nacionalidade, na tentativa de lá encontrar a solução para o impasse que ameaça lançá-la no outro extremo - a morte. A solução vislumbrada, então, diz respeito àquilo que é possível fazer tendo em vista a identidade que se construiu em torno dessa configuração, originalmente territorial, mas fundamentalmente cultural. As últimas palavras do narrador apontam para ela

Tenho visto alguma coisa do mundo e apontado alguma coisa do que vi. De todas quantas viagens porém fiz, as que mais me interessaram sempre foram as viagens na minha terra.

(...)

Nos caminhos-de-ferro dos barões é que eu juro não andar.

Escusada é a jura, porém.

Se as estradas fossem de papel, fá-las-iam, não digo que não.

Mas de metal!

Que tenha o governo juizo, que as faça de pedra, que pode, e viajaremos com muito prazer e com muita utilidade e proveito na nossa boa terra. ${ }^{14}$

12 GARRETT, op. cit., p.212.

13 Id.

14 Ibid. p. 213. 
CARDOSO, P. Garrett e seu convite à viagem

A imagem da viagem acompanha o narrador até o fim e espelha a possível solução para o impasse identificado por Garrett: o país deve construir estradas com o material que sabe utilizar, que conhece, ao invés de lançar-se em empreitadas em terrenos que não lhe dizem respeito.

Já no poema Camões, Garrett havia utilizado o tema da viagem para discutir questões relativas ao destino de Portugal. Nessa obra é significativo que Camões-personagem refaça pessoalmente a viagem de Vasco da Gama mas não consiga como ele um resultado satisfatório. Ele revive a experiência dos que pereceram contribuindo para engrandecer a pátria por meio da expansão marítima, mas sua viagem tem a função de mostrar a distância imensa entre os que lideraram a conquista de fundo humanista e aqueles que a transformaram em meio de enriquecimento. Nesse sentido, a experiência adquirida pelo Camões de Garrett é exclusivamente a da falência que advém do desvio de rota. Esses elementos, já presentes em Os Lusíadas, ganham uma nova força no Camões por não contemplarem a possibilidade de recuperação dos valores perdidos

\author{
Qu'é desse espírito que animava os fortes? \\ $Q u ' e ́$ desse vivo ardor de fama honrada \\ Que faiscava em lusitanos peitos, \\ E a arriscadas ações, a empresas grandes, \\ A mais que humanos feitos levava? \\ Extinguiu-se, acabou. Já formos Lusos; \\ Fomos: - de nossa glória o brado ingente \\ Breve será clamor que geme longe, \\ Como voz de sepulcros esquecidos \\ Balda soando no porvir que a ignora. ${ }^{15}$
}

Ao chegar ao seu destino, não é a glória que espera o poeta, mas a evidência de que as conquistas passadas perderam-se para sempre. É importante notar no trecho acima a transformação do passado em fantasmagoria que assombra mas não tem força para modificar o presente. Nesse sentido, o passado pode também ser um entrave na definição do futuro, uma vez que no presente os portugueses apenas conseguem identificar a falência de modelos anteriormente eficazes, mas não conseguem criar novos modelos, adequados a sua realidade cultural.

15 GARRETT, Almeida. Camões. In: Obras. Lisboa: Lello \& Irmão Editores, 1963 , v. 2 , p. 351 
Essa maneira de problematizar o confronto entre passado e presente pode ser vista também no momento das Viagens, anteriormente referido, em que o narrador, ao deixar Frei Dinis e Francisca, registra a impressão de ter estado diante da morte. Em outro ponto dessa mesma obra, referindo-se a Os Lusíadas, o narrador se pergunta se também o amor da pátria é uma fantasmagoria.

Eduardo Lourenço atribui a Garrett o papel de iniciador de um sistemático revolver sobre a história portuguesa cujo sentido seria procurar, $\mathrm{cm}$ meio a tantas falências, materiais e de ideais, um ponto qualquer em que os portugueses pudessem olhar e se enxergar como indivíduos portadores de uma característica que os identificasse, distinguindo-os como coletividade autônoma

\begin{abstract}
A partir de Garrett e Herculano, Portugal, enquanto realidade histórico-moral, constituirá o núcleo da pulsão literária determinante. (...) Mas é sob a pluma de Garrett que pela primeira vez, e a fundo, Portugal se interroga, ou melhor, que Portugal se converte em permanente interpelaçāo para todos nós. (...) Garrelt não pode saber quem é, nem o que verdadeiramente quer, sem interrogar a sério e de frente o que é essa realidade viva de uma Pátria entrevista como "frágil", "vulnerável" e da qual sente o ser interior e o seu destino pessoal inseparáveis. ${ }^{16}$
\end{abstract}

Caso o leitor tenha levado a sério a tarefa de descobrir qual o sentido encoberto do termo mito na narrativa das Viagens, terá aqui a chance de arriscar um palpite. Não seriam essas Viagens a consolidação do mito da identidade nacional, sem a qual, como diz Lourenço, seria impossivel para Garrett conhecer a si mesmo? Como bom viajante que é, Garrett tem seus olhos abertos para o que ainda está por ser encontrado e, com certeza, não gostaria que seus leitores fizessem afirmações categóricas a respeito do que seu viajante buscava e em que medida o encontrou. Entretanto, é difícil para o leitor livrar-se de algumas palavras de um narrador tão envolvente. Com elas termino este texto

A minha opinião sincera e conscienciosa é que o leitor deve saltar estas folhas, e passar ao capítulo seguinte, que é outra casta de capítulo. $^{17}$

16 LOURENÇO, Eduardo. Da literatura como interpretação de Portugal. In: . Labirinto da Saudade. Lisboa: Publicações Dom Quixote, 1992. p. 80-84.

17 GARRETT, Almeida. Viagens na minha terra. Lisboa: Europa-América, 1972, p. 24. 


\section{REFERÊNCIAS BIBLIOGRÁFICAS}

DE MAISTRE, Xavier. Viagem à roda de meu quarto. São Paulo: Estação Liberdade, 1989.

GARRETT, Almeida. Viagens na minha terra. Lisboa: Europa-América, 1972. . Obras. Lisboa: Lello \& Irmão Editores, 1963. v. 2.

LOURENÇO, Eduardo. Da literatura como interpretação de Portugal. In: .0 labirinto da saudade. Lisboa: Publicações Dom Quixote, 1992.

PAES, José Paulo. Stern ou o horror à linha reta. In: STERN, Laurence. A vida e as opiniöes do cavalheiro Tristram Shandy. Rio de Janeiro: Nova Fronteira, 1984. 